\title{
Desmistificação do regime contábil de competência*
}

\author{
Thiago Bernardo Borges** \\ Poueri do Carmo Mario*** \\ Ricardo Lopes Cardoso**** \\ André Carlos Busanelli de Aquino*****
}

\begin{abstract}
Sumário: 1. Introdução; 2. Desmistificando o regime de competência: conceito e aplicabilidade; 3. A análise da adoção do regime de competência; 4. Considerações finais.
\end{abstract}

Summary: 1. Introduction; 2. Debunking accrual-basis accounting; concept and applicability; 3 . Analyzing the adoption of accrual-basis accounting; 4. Final remarks.

Palavras-chave: contabilidade pública; regime de competência; nova administração pública.

\footnotetext{
* Artigo recebido em fev. e aceito em maio 2010.

** Especialista em políticas públicas e gestão governamental na Fundação João Pinheiro. Graduado em administração pública pela Escola de Governo Professor Paulo Neves de Carvalho e em ciências contábeis pela Universidade Federal de Minas Gerais. Endereço: Alameda das Acácias, 70, sala 318, 3o andar — São Luiz — CEP 31275-150, Belo Horizonte, Minas Gerais, Brasil. E-mail: thiago.borges@fjp.mg.gov.br.

*** Professor adjunto e coordenador do Mestrado em Ciências Contábeis da Falcudade de Ciências Econômicas da UFMG. Doutor e mestre em ciências contábeis pela FEA/USP. Endereço: Faculdade de Ciências Econômicas/UFMG, Av. Antônio Carlos, 6627 — Pampulha — CEP 31270-901, Belo Horizonte, Minas Gerais, Brasil. E-mail: poueri@face.ufmg.br.

**** Professor adjunto da Escola de Administração Pública e de Empresas da Fundação Getulio Vargas e da Faculdade de Administração e Finanças da Universidade do Estado do Rio de Janeiro. Doutor em ciências contábeis pela FEA/USP e mestre em ciências contábeis pela FAF/Uerj. Endereço: Escola Brasileira de Administração Pública e de Empresas/FGV, Praia de Botafogo, 190, sala 526 - Botafogo - CEP 22250-090, Rio de Janeiro, Brasil. E-mail: ricardo.lopes.cardoso@ fgv.br.

$* * * * *$ Professor associado da Faculdade de Economia, Administração e Contabilidade de Ribeirão Preto da Universidade de São Paulo. Doutor em ciências contábeis pela FEA/USP, mestre em engenharia de produção pela EESC/USP. Endereço: Faculdade de Economia, Administração e Contabilidade de Ribeirão Preto da Universidade de São Paulo, Av. Bandeirantes, 3900 - Monte Alegre — CEP 14040-905, Ribeirão Preto, São Paulo, Brasil. E-mail: aaquino@usp.br.
} 
KEY WORDS: government accounting; accrual accounting; new public management.

Este artigo apresenta o regime de competência de forma simples e objetiva, e discute como pode ser aplicado às organizações públicas no Brasil. Para tanto, usa a experiência do governo do estado de Minas Gerais no processo de preparação para a adoção do regime de competência puro, que desde 2001 estuda a possibilidade de adoção do regime. Esse processo foi acelerado em 2009 pela iminência de convergência às normas internacionais de contabilidade para o setor público, demandada pela Secretaria do Tesouro Nacional e pelo Conselho Federal de Contabilidade. A análise apresenta os incentivos à iniciativa da adoção do regime, mesmo antes da exigência legal, e os potenciais impactos de tal adoção no processo decisório. O processo de reforma administrativa no caso de Minas Gerais, incentivado primariamente pela necessidade de saneamento fiscal, levou à adoção do conceito de contratualização, o que passou a demandar informação de desempenho. Apesar dos benefícios em potencial do regime de competência para decisão e accountability, o Estado necessitará enfrentar questões como capacitação, adequação de sistemas e incertezas quanto aos parâmetros da Lei de Responsabilidade Fiscal.

\section{Debunking the accrual-basis accounting}

This paper presents accrual basis accounting in a straight and objective way, and how it can be applied to the Brazilian public sector. The State of Minas Gerais has been preparing itself to adopt the accrual accounting since 2001. This process has been improved since 2009 as a consequence of the joint work between the Brazilian Treasury and the National Institute of Chartered Accountants that aim to converge the Brazilian public sector accounting standards to the International Public Sector Accounting Standards. The analysis presents the incentives to the adoption of the accrual accounting, even before it becomes mandatory, and the potential effects of that adoption on decision making. The Minas Gerais public reform was a consequence of public deficits and the need to cut expenses. It drove the State to establish performance contracts that demand performance information. Although accrual accounting might provide benefits for decision making and accountability, the public sector will need to face some issues, as training, technological barriers and uncertainties related to the thresholds of the public finance legislation.

\section{Introdução}

A contabilidade, por ser um sistema de informação e avaliação, tem por objetivo "prover seus usuários com demonstrações e análises de natureza econômica, financeira, física e de produtividade, com relação à entidade objeto de contabilização" (Iudícibus, Martins e Gelbcke, 2000:42). Por sua vez, a contabilidade pública registra, controla e demonstra a execução dos orçamentos, 
dos atos e fatos da fazenda pública e o patrimônio público e suas variações (Kohama, 2001). Assim tem como propósito gerar informação aos diversos interessados no desempenho e no patrimônio das entidades públicas.

A crise do Estado, iniciada em quase todo o mundo na década de 1970, trouxe dificuldades fiscais, o esgotamento do modelo de gestão utilizado e intensificou os debates referentes à administração pública. Principalmente quanto à discussão de qual o papel do Estado na provisão dos serviços públicos e se a burocracia seria a forma mais eficaz para o funcionamento e controle das atividades estatais. Os argumentos a favor da mudança eram de que o modelo burocrático de gestão tornara-se ineficiente na administração dos recursos públicos e no atendimento das necessidades e demandas da sociedade (Oliveira, 2006:8). Para autores como Bresser-Pereira (1998), Cardoso (1998) e Rezende (2002), o movimento de reorganização do sistema econômico e político mundial, também conhecido como globalização, trouxe repercussões nos modelos de gestão pública e passou a exigir dos governantes a discussão sobre os novos rumos a serem adotados.

Assim, a partir da década de 1980, o que se percebe no mundo é a discussão e adoção de reformas administrativas focalizando a qualidade do gasto público, além de mudanças institucionais e de gestão.

No Brasil, em 1995, iniciou-se a implantação de uma reforma gerencial no governo federal, através do Plano Diretor de Reforma do Aparelho do Estado (Pdrae). Tal documento defendeu a modernização da administração pública e o fortalecimento da capacidade de gestão do Estado, como uma solução à crise do Estado brasileiro. O Pdrae foi produzido pelo Ministério da Administração Federal e Reforma do Estado (Mare), órgão criado para pensar e executar a reforma, que esteve sob o comando do professor Bresser-Pereira. A constituição do Mare representou um movimento em direção à adesão aos postulados e princípios da administração pública gerencial, tendo como principal mudança o sistema de controle, que deixa de se basear estritamente nos processos para se concentrar nos resultados (Franco, 2004).

Para que a reforma gerencial fosse concretizada os gestores deveriam atuar em três dimensões principais: a institucional-legal, com o intuito de renovar instituições normativas e organizacionais que facilitassem a gestão do bem público; a cultural, que busca uma quebra dos conceitos arraigados da cultura burocrática para a gerencial; e a gestão, que objetiva a introdução de novas ideias e práticas gerenciais, marcadas pela busca de serviços públicos de qualidade e pela redução nos custos da prestação desses serviços (Bresser-Pereira, 1996).

Nesse contexto, desde 2002, o estado de Minas Gerais vem passando por um processo de modernização da administração pública, denominado 
Choque de Gestão, com o intuito de substituir o modelo da administração pública burocrática por um que visa à utilização mais eficiente dos recursos públicos. O modelo burocrático é definido por Bresser-Pereira (1996) como "lento, caro, autorreferido, pouco ou nada orientado para o atendimento das demandas dos cidadãos". O novo modelo se caracterizou por trazer algumas metodologias aplicadas até então na iniciativa privada, para dentro da administração estadual mineira. Para tanto, foram definidas cinco frentes de atuação: crescimento de receita, redução de despesa, reestruturação de processos de trabalho, gerenciamento de projetos públicos e efetivação do planejamento e da estratégia na gestão pública (Oliveira, 2006).

Para cada frente de atuação foram estabelecidas metas de desempenho, algumas delas atreladas a informações contábeis. Contudo, não se verificou a utilização dessas informações para se estruturar cenários situacionais de cada programa de governo. Pelo menos, nenhum documento é publicado pelo governo contendo tais análises. Portanto, resta a dúvida: se as frentes de atuação decorrentes do Choque de Gestão têm metas de desempenho atreladas à informação provida pela contabilidade pública, por que o Estado não disponibiliza informações quanto ao monitoramento do desempenho de tais programas? Talvez a contabilidade pública não seja percebida pelo gestor público como uma fonte adequada de informações úteis à gestão pública, conforme sugerem Alonso (1999) e Tibúrcio (2007), citados por Borges (2008). ${ }^{1}$

Nesse cenário, o termo "confiabilidade da informação" acaba viesado para o conceito de conformidade às regras, ao contrário do conceito de que a sustância econômica deve prevalecer sobre a forma. Nessa linha, a adoção do regime de caixa tende a ser preferível, já que a receita só é reconhecida quando arrecada e não se reconhece provisionamento para contingências. Ao se evitar o reconhecimento de direitos sobre expectativas de fluxos de caixa cuja mensuração é, por natureza, mais subjetiva que a do fluxo de caixa efetivo (isso para só falar do lado da receita), gera-se informação muito mais fácil de ser auditada (fiscalizada), reduzindo-se riscos e custos de transação ex post.

\footnotetext{
${ }^{1}$ Isso pode ser uma consequência do suposto fato de contadores e gestores públicos se dedicarem com mais (ou exclusiva) ênfase na elaboração de demonstrações (contas) que sejam aprovadas pelos órgãos de controle (Tribunal de Contas), que em gerar informações úteis à gestão da coisa pública, o que não é exclusivo das entidades públicas. É senso comum que empresas de pequeno e médio portes se ocupam mais com a geração de informações para o fisco do que para a própria gestão. Se de um lado o gestor público se preocupa com o Tribunal de Contas, de outro o gestor de empresas privadas se preocupa com o Fisco.
} 
Por outro lado, analisando-se países que iniciaram o processo de reforma do Estado, encontram-se experiências de jurisdições em estágio avançado de geração e uso de informações gerenciais pela administração pública. De acordo com os relatos desses países, nota-se que a informação pelo regime de caixa não é adequada à geração de informações para uso gerencial e, por essa razão, tais países tendem a adotar o regime de competência (Carlin, 2003). Também conhecido por accrual accounting, o regime de competência é "o regime contábil segundo o qual transações e outros eventos são reconhecidos quando ocorrem (não necessariamente quando o caixa ou seus equivalentes são recebidos ou pagos)." (Ipsas $\left.1, \S 7^{\circ}\right) .^{2}$

Em termos comparados, o regime de caixa apresenta desvantagens como: a informação tem escopo limitado, não adequado para demonstrar o impacto de transações resultando no fluxo de caixa fora do período corrente do relatório; o regime é incapaz de encontrar as demandas por informações de ativos e obrigações, e o impacto do consumo corrente dos estoques de ativos governamentais, por tipos de transações e áreas; tem foco somente no fluxo de caixa, ignorando outros fluxos que podem também afetar a habilidade governamental de prover bens e serviços no momento atual e no futuro; gera uma limitada transparência em relação ao uso do recurso financeiro na gestão de ativos e obrigações (Diamond, 2002).

\footnotetext{
${ }^{2}$ Em 2009 a European Accounting Review dedicou uma seção especial para o tema (Special section: "The adoption of accrual accounting in the public sector"). Entre os estudos publicados fica evidente que a questão é bem mais ampla do que a argumentação do ganho de relevância da informação. Lapsley e colaboradores (2009) continuam destacando a disseminação do NPM, assim como as pressões geradas pela adoção do regime de competência. Os autores alertam para que nem mesmo a definição de ativos no caso do setor público tem sido razoavelmente tratada no processo de adoção do regime de competência. Os autores discutem se praças e monumentos deveriam ser tratados como "ativo" ou como "obrigações", já que consomem caixa ao invés de gera caixa. Outra questão tratada é a recorrência de alterações dos padrões contábeis exigidos para serem adotados pelos governos locais (custos financeiros, políticos e sociais associados com as mudanças), e a consequente preocupação com a manipulação da informação contábil para atingir metas fiscais (Pilcher e Dean, 2009). Mellett e coautores (2009) identificaram que, na entidade que administra o serviço de saúde pública do Reino Unido (NHS), o conceito de regime de competência não é difundido além do nível da administração superior, de forma que os gestores a partir do segundo escalão são indiferentes quanto ao regime contábil adotado, não obstante o fato de o regime de competência estar sendo implantado não só na contabilidade financeira, mas para fins de elaboração orçamentária. Ainda, a adoção do regime de competência e sua efetividade guardam relação com o nível de participação popular, transparência, accountability, processos orçamentários e mecanismos de monitoramento (Pina et al., 2009). Por fim, a implantação não é uma questão trivial, tampouco ausente de conflitos (Arnaboldi e Lapsley, 2009).
} 
Por sua vez, o accrual accounting procura refletir o custo total do serviço prestado, o que seria a base da produção de indicadores de desempenho para fins de controle e avaliação do gasto público (Saleh e Pendlebury, 2006).

Entre as razões que defendem a migração do regime de caixa para o regime de competência, o estudo 11 do Ifac (2000) destaca a necessidade de aumentar o conteúdo informacional e atender as diversas necessidades dos gestores públicos em termos de decisão e controle. O que implicaria evidenciar (a) fontes e tipos de receitas; (b) alocação e uso dos recursos; (c) receitas seriam suficientes para cobrir quais operações; (d) predição de tempo e volume de caixa, além de necessidades futuras de empréstimos; (e) capacidade de honrar as obrigações futuras; (f) desempenho financeiro do governo e das entidades governamentais na utilização de seu orçamento; (g) impactos econômicos do governo na economia; (h) opções de gasto do governo e suas prioridades; (i) análise da execução do orçamento. Esses pontos envolvem dois aspectos. Primeiro, uma melhoria na qualidade da informação para decisão, já que, como colocado por Diamond (2002), boas informações sobre o custo total da provisão de serviços permitem aos governos a realização de estimativas mais confiáveis da necessidade de recursos de investimentos a serem propostos, proporcionando melhor alocação dos recursos públicos. Segundo, a adoção do regime de competência gera incentivos aos gestores públicos para melhor utilizar o recurso e aumenta a transparência. A responsabilização e a transparência das atitudes dos gerentes aumentam quando eles passam a responder não apenas pelo dinheiro que gastam, mas também pelos ativos e passivos que administram. Tratar de forma explícita os bens, direitos e obrigações aumenta o controle fiscal. Transações não monetárias, como reconhecimento de dívidas de empresa estatais, criação de obrigações de custeio, que causaram impacto econômico, deverão ser registradas e reportadas no regime de competência, fato que permitirá uma visão ampla dos custos de manutenção de todo o governo.

O regime de competência tem sido adotado em vários países. Desde uma implantação do regime de competência puro, como no Japão, Países Baixos, Nova Zelândia, Portugal, Suécia, Suíça, Reino Unido, Estados Unidos, Austrália e Finlândia, até versões modificadas do regime de competência como nos exemplos do Canadá e da Islândia. Ainda são observados alguns países que adotam o regime de caixa, porém com dados complementares ao do regime de competência, como Irlanda, Hungria, Alemanha e Bélgica (OECD, 2002). No Brasil, o modelo adotado é considerado misto, por utilizar regime de competência para as despesas, enquanto o regime de caixa é utilizado para as receitas. Tal modelo, assim como o regime de caixa, é criticado na literatura 
especializada. Desse modo, o que se quer é difundir o conhecimento acerca do modelo de accrual accounting, explicitando seus principais benefícios em um contexto de controle por resultados, como exposto por Diamond (2002).

Dados esse movimento mundial e a posição comparada do Brasil nesse cenário, assim como o cenário multivariado nos estados brasileiros, este artigo desmistifica o regime de competência a ser adotado no Brasil, e, através de um breve relato da experiência do governo do estado de Minas Gerais, levanta questões sobre a adoção e implantação de tal regime.

Para tanto, o artigo parte de entrevista realizada em profundidade com a gestora da contabilidade do estado de Minas Gerais, e através de observação direta do autor principal na função de especialista em políticas públicas e gestão governamental da gestão do estado. A abordagem descritiva adotada (Martins e Theophilo, 2007), aplicada na fase exploratória do tema de pesquisa no Brasil, objetiva levantar pontos relevantes à questão de implantação do atual regime nas organizações públicas brasileiras.

A seguir o artigo procura desmistificar a questão do regime de competência para administração pública. Em seguida, apresenta a experiência de Minas Gerais na reforma do Estado e na análise dos potenciais benefícios que tal adoção traria. Por fim, algumas condições a serem alcançadas são levantadas e deveriam ser alvo de maior reflexão, sob pena do regime adotado não ter coerção ou utilidade suficientes.

\section{Desmistificando o regime de competência: conceito e aplicabilidade}

Diferentemente do senso comum, em contabilidade, o termo "competência" tem um significado muito peculiar. Não guarda qualquer relação com o poder investido, com a ideia de autoridade, capacidade, atribuição, direito ou faculdade legal que um indivíduo ou tribunal tem de apreciar e julgar um pleito ou uma questão. Em contabilidade, o termo "competência" é associado ao reconhecimento de uma transação ou outro evento em determinado período. Daí porque também costuma ser chamado de "regime de competência de períodos".

Em inglês, a contabilidade pelo regime de competência é conhecida por accrual basis accounting. O substantivo accrual deriva do verbo to accrue que significa: "1. to happen or result as a natural growth, addition etc.; 2. to be added as a matter of periodic gain or advantage, as interest on money." Portanto, to accrue significa a adição, ganho ou resultado periódico decor- 
rente de crescimento natural ou juros. Sua origem é atribuída a meados do século XV. Em francês antigo sua grafia era acrue e em latim accrescere, e sempre significou crescimento, incremento, aumento. Remontando ao século $\mathrm{XV}$, quando a agricultura era uma das principais atividades econômicas, fica mais fácil compreender o sentido do regime de competência. O agricultor percebia que estava mais rico conforme sua cultura (plantação ou criação — qualquer ativo biológico) crescia. Portanto, mesmo que ele não realizasse qualquer transação de venda ou colheita, sem qualquer transação financeira (pagamento ou recebimento), ele podia mensurar o seu desempenho como a variação de seu patrimônio durante o período. Afinal, à luz do conceito de "renda" apresentado por John Richard Hicks em 1939, o desempenho (income) da entidade em determinado período pode ser medido pela comparação do valor de seu patrimônio entre o início e o final de tal período. Portanto, conforme a cultura cresce (acrue, accrescere) o agricultor pode reconhecer o ganho periódico (accrual).

Como o agricultor mede o crescimento de sua cultura periodicamente (por exemplo, todo mês), costuma-se dizer que o crescimento da cultura no mês de janeiro dá origem ao ganho que compete àquele mês. Daí porque o termo "regime de competência de períodos".

Os padrões internacionais de contabilidade emitidos pelo International Accounting Standards Board (Iasb) e pelo International Public Sector Accounting Standards Board (Ipsasb) relativos ao agrobusiness seguem essa lógica até hoje, com a sofisticação de que o ativo biológico é mensurado com base no "valor justo menos os custos de venda". Sendo o valor justo determinado pelo preço de cotação no mercado ativo no qual a entidade costuma transacionar (para detalhes, vide os $\S \S 34.2-34.10$ do IFRS para SMEs, o IAS 41 e o Ipsas 27).

Caso o agricultor adotasse outro regime contábil — o regime de caixa - , só reconheceria o ganho quando recebesse o dinheiro da venda do produto derivado da colheita.

Para compreender o regime de competência, é necessário conhecer o propósito da contabilidade. O Iasb apresenta que o objetivo das demonstrações contábeis é "oferecer informações sobre a posição financeira, o desempenho e fluxos de caixa das entidades a uma vasta gama de usuários que não têm condições de exigir relatórios feitos sob medida para atender suas necessidades informacionais" (IFRS, §2.4, livre tradução). Objetivo semelhante é apresentado pelo Ipsasb no $§ 3^{\circ}$ da Ipsas 1 , em relação às demonstrações contábeis elaboradas pelas entidades do setor público. 
A posição financeira apresentada pelo Iasb e pelo Ipsasb consiste na situação do patrimônio da entidade em determinado momento, e o desempenho é medido conforme sugerido por Hicks (1939), como a variação do patrimônio entre duas datas. Portanto, o conceito de patrimônio é fundamental para se compreender o regime de competência.

Pelo jargão contábil, o conceito de patrimônio é representado pelo termo ativo - cujo emprego não guarda qualquer relação com o senso comum. Para o Iasb e o Ipsasb, "ativos são recursos controlados por uma entidade em consequência de eventos passados e dos quais se espera que resultem fluxos de benefícios econômicos futuros ou potencial de serviços para a entidade" (Ipsas 1, §7으, livre tradução; IFRS for SMEs, §2.15 do; Iasb, §49).

Ao se questionar como o regime de competência se aplica às entidades públicas, é razoável supor que a principal fonte de financiamento de estados não seja, por exemplo, uma atividade agrícola, mas o recolhimento de tributos.

Assim, quando uma prefeitura municipal calcula o valor do IPTU, identifica os contribuintes e emite os boletos de cobrança (no jargão do direito tributário, a prefeitura "lança o tributo"), o patrimônio da prefeitura cresce (acrue, accrescere) - pois tem o direito de receber o tributo dos contribuintes — em razão do lançamento do IPTU. Naquele momento a prefeitura já teria condições de reconhecer a receita (pelo regime de competência) decorrente desse tributo, pois é capaz de individualizar o crédito e mensurar o valor que tem a receber. Como nenhum dinheiro entrou em caixa ainda, a prefeitura precisa reconhecer o acréscimo patrimonial como tributos a receber. Se a prefeitura adotasse o regime de caixa, só reconheceria o tributo quando o contribuinte efetivamente pagasse sua dívida, seja em cota única (digamos em fevereiro) seja mensalmente (se optasse pelo pagamento parcelado).

Diferente do IPTU, que tem baixa incerteza por causa da pouca variação no cadastro dos imóveis, ano após ano, o reconhecimento de impostos associados à prestação de serviços e venda de mercadorias pode ser um desafio para a administração pública. O contribuinte de ICMS, ao vender, seja à vista ou a prazo, dá origem ao fato gerador do ICMS e é obrigado a preencher uma série de formulários (obrigações acessórias), além de recolher (pagar) o ICMS até a data do vencimento (normalmente, no mês subsequente à data da venda). Assim que o Estado tiver conhecimento que tal transação ocorreu (por exemplo, mediante os formulários enviados pelo contribuinte), o Estado identifica que seu patrimônio está maior que antes (acrue, accrescere) - pois tem o direito de receber o tributo do contribuinte. Portanto, deve reconhecer o acréscimo patrimonial (tributos a receber) e a receita respectiva, antes mesmo que o contribuinte pague sua dívida. Com a 
implantação da nota fiscal eletrônica, parte dos procedimentos relativos às citadas obrigações acessórias será significativamente simplificada e o Estado terá acesso à informação da ocorrência do fato gerador (venda) quase no mesmo tempo que a ocorrência do evento econômico que suscitou a entidade mercantil (contribuinte) reconhecer sua receita.

Seguindo a mesma lógica, o regime da competência também é utilizado para se reconhecer as despesas - o que importa é a ocorrência do evento econômico e o surgimento da obrigação (passivo).

Digamos que os funcionários de determinada repartição pública tenham direito a 30 dias de férias remuneradas por ano. Mensalmente, essa repartição deve reconhecer como despesa de pessoal não só o salário do mês (que será pago nos primeiros dias do mês subsequente), mas também $1 / 12$ relativo ao direito aquisitivo de seus funcionários gozarem férias no futuro. Essa despesa é reconhecida em contrapartida ao passivo (salários e benefícios a pagar). Parte desse passivo deverá ser paga no início do mês seguinte, o salário; parte deverá ser paga ao longo dos próximos 12 meses, conforme os servidores saírem de férias. Caso essa entidade pública adotasse o regime de caixa, o salário de um mês só seria reconhecido como despesa no mês seguinte (na data do pagamento) e as férias seriam integralmente reconhecidas como despesa na data que o servidor recebesse a remuneração de férias (o que poderia ocorrer, por exemplo, no final do ano).

Para finalizar, só mais um exemplo típico de aplicação do regime de competência para se reconhecer despesas. Quando uma delegacia de polícia adquire uma viatura à vista, pelo regime de caixa o valor total pago pela viatura é reconhecido como despesa na data da aquisição (pagamento). Dessa forma, o gestor público precisa utilizar registros extracontábeis para acessar informações relativas à necessidade de reposição da frota. Adotando-se o regime de competência, a viatura é reconhecida como um ativo e é depreciada ao longo de sua vida útil, digamos, de quatro anos. Assim, a cada mês, se nada extraordinário ocorrer com a viatura, é reconhecida a despesa relativa a $1 / 48$ do custo de aquisição, e a informação contábil sinaliza a necessidade de renovação da frota.

Quando a entidade utiliza o regime de competência para reconhecer despesas, mas utiliza o regime de caixa para reconhecer receitas, diz-se que ela adota o regime misto. $O$ regime de competência para reconhecer receitas e despesas é conhecido como regime de competência puro.

Talvez o leitor esteja se perguntando: se o regime de competência é tão simples, por que não é amplamente utilizado pelas entidades do setor público há tanto tempo quanto é utilizado pelas empresas privadas? 
É uma boa pergunta. Embora este artigo não tenha por objetivo desvendar as razões da não adoção do regime de competência no setor público, a seguir são propostas algumas sugestões. A lei que rege a contabilidade pública (tanto orçamentária quanto patrimonial), Lei oํ 4.320/1964, não é explícita quanto à necessidade de se adotar o regime de competência, embora a seção que trata da contabilidade patrimonial possa ser interpretada à luz do regime de competência.

Apesar de o critério básico para reconhecimento da receita, como apresentado, ser o crescimento (acrue, accrescere) do patrimônio, o contador precisa exercer julgamento para identificar se o patrimônio cresceu e para mensurar tal crescimento. Na atividade agrícola, o crescimento pode ser identificado visualmente e mensurado, por exemplo, mediante a variação do peso do gado ou da quantidade de frutos pendentes.

$\mathrm{Na}$ atividade mercantil, o crescimento patrimonial é objetivamente identificado quando a empresa vende mercadorias por preço superior ao custo de aquisição, quer a empresa venda a mercadoria à vista ou a prazo. Caso a venda seja a prazo, é necessário julgar a probabilidade de recebimento do dinheiro da venda. É razoável esperar que, para vender a prazo, a empresa avaliou a situação creditícia do cliente (por exemplo, consultou bancos de dados como o Checkcheck ou Serasa). Num caso extremo em que a empresa perceba, logo após realizar a venda a prazo, que não tem qualquer expectativa de receber o dinheiro da venda, identifica que seu patrimônio não cresceu (pelo contrário, entregou a mercadoria - o estoque diminui, mas o cheque jamais será compensado), então a empresa não deverá reconhecer qualquer receita relativa a essa venda, mas somente a perda (baixa do estoque).

Com relação ao reconhecimento da receita decorrente da tributação (também chamada receita decorrente de transações sem contraprestação), talvez a falta de informação sobre a ocorrência do fato gerador; a dificuldade de se mensurar o valor dos tributos a receber, uma vez que a ocorrência do fato gerador foi adequadamente identificada; e a incerteza quanto ao efetivo recebimento do tributo tenham motivado os contadores e gestores públicos a adiar o reconhecimento da receita tributária para a data do efetivo recebimento do dinheiro. Portanto, a falta de informação acaba sendo utilizada como justificativa para se adotar o regime de caixa para o reconhecimento de receitas.

Talvez essas justificativas tenham sido razoáveis há 45 anos, quando a Lei no 4.320 entrou em vigor. Entretanto, no cenário atual, com a vigência da Lei de Responsabilidade Fiscal e em que se implanta o sistema público de escrituração digital (Sped), o contribuinte (por exemplo, empresa mercantil) ao realizar a venda transmite, eletronicamente, à Secretaria da Fazenda (Sefaz) uma solici- 
tação de emissão de nota fiscal para uma determinada operação. A Sefaz valida alguns dados e, se todos os requerimentos forem observados, transmite ao contribuinte a autorização de emissão da nota fiscal. Além da nota fiscal eletrônica, o Sped compreende ainda a escrituração contábil digital, segundo a qual as informações contábeis do contribuinte (contabilidade tributária) são transmitidas em meio eletrônico e periodicamente à Sefaz e à Junta Comercial.

O avanço tecnológico ocorrido na última década reduz a assimetria informacional entre o ente público e os contribuintes, propiciando estimativas acuradas quanto ao crescimento patrimonial da entidade pública e a probabilidade de efetivo recebimento do dinheiro. Portanto, a falta de informação parece não ser mais uma justificativa plausível para o reconhecimento de receitas tributárias pelo regime de caixa.

Tampouco a regulamentação das políticas contábeis aplicáveis às entidades do setor público. Embora o atual regulamento do sistema de contabilidade federal, Decreto no 6.976/2009, não apresente o termo "regime de competência" de forma expressa, pelo menos dois trechos do decreto permitem somente uma interpretação: a de que o regime da competência é obrigatório para as entidades do setor público.

Art. 3o - O Sistema de Contabilidade Federal tem por finalidade, utilizando as técnicas contábeis, registrar os atos e fatos relacionados com a administração orçamentária, financeira e patrimonial da União e evidenciar:

V - a situação patrimonial do ente público e suas variações, decorrentes ou não da execução orçamentária, inclusive as variações patrimoniais aumentativas no momento do fato gerador dos créditos tributários;

Art. $7^{\circ}$ - Compete ao órgão central do Sistema de Contabilidade Federal:

I - estabelecer normas e procedimentos contábeis para o adequado registro dos atos e dos fatos da gestão orçamentária, financeira e patrimonial dos órgãos e entidades da administração pública, promovendo o acompanhamento, a sistematização e a padronização da execução contábil;

II - manter e aprimorar o Plano de Contas Aplicado ao Setor Público e o processo de registro padronizado dos atos e fatos da administração pública;

XXVII - identificar as necessidades de convergência aos padrões internacionais de contabilidade aplicados ao setor público;

XXVIII - editar normativos, manuais, instruções de procedimentos contábeis e plano de contas aplicado ao setor público, objetivando a elaboração e publicação de demonstrações contábeis consolidadas, em consonância com os padrões internacionais de contabilidade aplicados ao setor público; e 
XXIX - adotar os procedimentos necessários para atingir os objetivos de convergência aos padrões internacionais de contabilidade aplicados ao setor público.

Observe que o órgão central do sistema de contabilidade federal é a Secretaria do Tesouro Nacional do Ministério da Fazenda, e que esta já iniciou, em parceria com o Conselho Federal de Contabilidade, o processo de convergência das normas contábeis brasileiras aplicáveis ao setor público aos padrões internacionais de contabilidade (Ipsas). A Ipsas 23 estabelece as orientações para se reconhecer e mensurar a receita tributária pelo regime de competência (especificamente no §44 e §49).

Em razão dos citados avanços tecnológicos e regulamentares, não há mais justificativa para se reconhecer a receita tributária pelo regime de caixa. Talvez o que falte seja a mudança de paradigma, afinal o contador e o gestor público podem se perguntar: por que vou mudar procedimento que já adoto há mais de 40 anos e sempre funcionou? Essa questão envolve a percepção de relevância da informação contábil. Espera-se que o movimento liderado pelo Ministério da Fazenda, mais intensamente durante o período 2008-2010, para que se comece a apurar informações de custos por todas as entidades do setor público federal alavanque a percepção da relevância da informação pelo regime de competência. Afinal, o atual sistema de informação de custos transforma os dados disponibilizados nos sistemas estruturantes relativos ao momento da liquidação em informação baseada no regime de competência, para só então iniciar o processo de apuração de custos. Uma vez que a contabilidade financeira (patrimonial) das entidades públicas já seja gerada com base no regime de competência, tal transformação não será mais necessária e a informação tenderá a ser mais acurada (não será mais baseada numa aproximação).

Enquanto a estrutura conceitual básica da informação de custos do setor público tem como pressuposto a adoção do regime de competência, a implantação do sistema de informação de custos serve como incentivo à adoção do regime de competência.

A próxima seção apresenta os procedimentos adotados pelo governo do estado de Minas Gerais para se preparar para a adoção do regime de competência.

\section{A análise da adoção do regime de competência}

A adoção (decisão inicial), implantação (efetiva realização das medidas) e coerção para manutenção do uso do regime dependem de fatores externos às organizações públicas e ao governo como um todo, e de incentivos internos 
às organizações. A literatura de difusão de instrumentos gerenciais tem sido proeminente em indicar que nem todo sistema adotado é utilizado (Lapsley e Wright, 2004). A adoção não se dá apenas na Secretaria da Fazenda do governo central, seja na esfera federal ou estadual, mas sim nas diversas instâncias do governo. Portanto, a difusão pode ser feita compulsoriamente ou voluntariamente. Contudo, a compulsoriedade pode levar à implantação, mas não necessariamente ao uso efetivo. A difusão de uma ferramenta gerencial (como por exemplo, o regime de competência) se converte em adoção condicionada a fatores como potenciais benefícios agregados, a consistência da tecnologia com as práticas e valores existentes, a complexidade da tecnologia, o potencial de uma implantação experimental e facilidade de observação dos benefícios (Lapsley e Wright, 2004). Ou seja, a conversão entre difusão e adoção (efetiva) é moderada pela utilidade percebida da "inovação".

Na Nova Zelândia, a adoção foi recomendada em 1978 pelo Controller and Auditor-General, mas apenas em 1993 a adoção foi efetivamente estendida para as mais de 3 mil entidades públicas no país. A adoção desse regime, associado à apuração de custos, aumentou o volume de informações de custos para o processo decisório e permitiu a comparabilidade entre departamentos do serviço público naquele país (Pallot, 1998). Contudo, a adoção de regime de competência e de sistemas de custos não gera o mesmo grau de utilidade e uso da informação nas diversas instâncias do governo, como na Holanda, em que unidades autônomas fazem maior uso da informação que municípios (Bogt e Helden, 2000).

O grau de utilidade está associado à contribuição da informação gerada, por exemplo para lidar com as incertezas orçamentárias (Geiger, 1995; Geiger e Ittner, 1996; Rockness e Shields, 1986). Além do grau de utilidade da informação, a adoção pode surgir para legitimação da organização pública ao atender exigências externas de instâncias superiores (Covaleski et al., 1985; Lapsley, 1994; Geiger e Ittner, 1996).

Apesar dos pontos positivos sempre destacados pelos defensores da adoção do regime de competência, os governos enfrentarão dificuldades na migração do regime, entre elas capacitação, integração da nova informação a outros processos de gestão pública (como processo orçamentário) e adequação de base de dados e sistemas informacionais envolvidos. Todos esses são processos lentos e complexos que envolvem centenas de organizações e parte da estrutura do governo, com diversas naturezas de serviços e estruturas.

Como exemplo brasileiro, podemos citar o caso do estado de Minas Gerais, que em 2003 iniciou um choque de gestão como resposta a uma crítica situação financeira, decorrente de uma década de déficits fiscais crônicos, endividamento crescente, despesas orçamentárias sem cobertura financeira, acarre- 
tando sérias dificuldades com fornecedores. Isso tudo associado à ausência de instrumentos de controles gerenciais, especialmente de planejamento e orçamento. Tendo como principais metas o ajuste fiscal, o desenvolvimento econômico, político e social do estado em bases sustentáveis no longo prazo (Franco, 2004), o choque de gestão estimularia as relações de governança contratuais, a partir da adoção de contratos de gestão que registravam compromissos negociados entre as partes, incluindo metas, objetivos e impactos esperados (Peci et al., 2008). Tal contratualização, assim como o acordo de resultados derivado dela, teriam por objetivo alinhar as organizações governamentais com a orientação estratégica do governo, através da autonomia das unidades (Furtado, 2007:22) comprometidas com orçamentos realistas e gerenciamento intensivo dos recursos e projetos do governo.

O programa em si partiu da elaboração de compromissos de longo prazo (Plano Mineiro de Desenvolvimento Integrado, Plano Plurianual de Ação Governamental), legitimados pela Constituição do Estado. Ambos os documentos estabeleciam prioridades e conjunto de ações estratégicas que suportariam a alocação de recursos nos anos seguintes. ${ }^{3}$ A operacionalização e a institucionalização do programa contaram com a criação de estruturas organizacionais adicionais no quadro do governo do estado e a adoção de gestão por projetos.

A criação de uma área específica para coordenar os projetos (Superintendência Central de Gestão Estratégica de Recursos e Ações do Estado - SCGeraes) pretendia intensificar e especializar a atividade de gestão dos projetos estruturadores (Guimarães e Almeida, 2006). Essa área emite o relatório de situação (status report), consolidando as informações dispersas de forma padronizada, e desdobrando-as em outros instrumentos gerenciais encaminhados ao alto escalão do governo, para subsidiar o processo decisório da alta administração do Executivo estadual (Timoteo, 2005:57).

Paralelamente, uma área foi criada para desenhar a modernização do governo (Superintendência Central de Modernização Institucional — Sumin). Essa área tem por finalidade propor, coordenar e supervisionar as atividades e projetos relativos à racionalização, modernização e reestruturação do Poder Executivo, garantindo um processo de permanente inovação da gestão insti-

\footnotetext{
${ }^{3}$ Os documentos incluem: os chamados "indicadores finalísticos", para cada área de resultado, que estabelecem metas em um horizonte de 10 anos; uma carteira de ações chamadas "projetos estruturadores" para um horizonte de três anos; um diagnóstico e uma proposta de agendas de gestão por área de resultados, desdobrados em agendas setoriais por secretaria, contendo iniciativas que removam os gargalos críticos de gestão à realização da estratégia; metas de desempenho, incluindo produtividade e qualidade do gasto para cada área de resultados.
} 
tucional, condicionado às mudanças ambientais. Por fim, o governo mineiro lançou mão do slogan — Estado para Resultados ${ }^{4}(\mathrm{EpR})$ - , vendo cada área de resultado com projetos a ser gerenciados dentro de seu portfólio. A equipe responsável por coordenar tal programa tem como objetivos: apurar e avaliar os indicadores finalísticos com objetivo de monitorar e captar as mudanças para a sociedade; monitorar os indicadores de desempenho com objetivo de gerenciar a qualidade do gasto público; gerenciamento de restrições relevantes para o alcance dos resultados, através do acompanhamento seletivo das macrometas dos projetos estruturadores e da agenda setorial do choque de gestão; conduzir análise estratégica da Carteira de Projetos Estruturadores; prover apoio na implementação dos projetos estruturadores através da alocação de empreendedores públicos com plano de ação contratado; acompanhar o planejamento estratégico de alguns sistemas operacionais.

Embora o regime de competência ainda não tenha sido adotado pelo estado de Minas Gerais, a secretária da Sefaz-MG estima que os pontos positivos da adoção do regime de competência puro naquele estado estariam associados a potenciais: melhoria da qualidade da informação; ganho de accountability, e sinalização de melhoria de gestão e diminuição de risco de crédito pelo aumento da transparência. O quadro sumariza os potenciais benefícios da adoção em relação às funções desempenhadas pelas estruturas estratégicas implantadas pelo governo de Minas Gerais.

\section{Benefícios potenciais da adoção do regime de competência puro para o governo de Minas Gerais}

\begin{tabular}{|lll|}
\hline $\begin{array}{l}\text { Estrutura de } \\
\text { governança }\end{array}$ & \multicolumn{1}{c|}{ Funções } & $\begin{array}{c}\text { Benefícios da utilização do regime de } \\
\text { competência puro }\end{array}$ \\
\hline SCGeraes & Monitorar projetos & $\begin{array}{l}\text { Apuração do custo/benefício da } \\
\text { implementação dos projetos }\end{array}$ \\
& Liberar recursos financeiros & $\begin{array}{l}\text { Visão dos impactos no custeio devido } \\
\text { à aquisição de bens permanentes e }\end{array}$ \\
& contratações \\
& Apuração dos custos financeiros das \\
& solicitações de mudança de escopo dos \\
& projetos \\
\hline
\end{tabular}

Continua

\footnotetext{
${ }^{4}$ Programa instituído através da Lei Delegada no 112 , ressalta-se o caráter temporário dessa estrutura.
} 


\begin{tabular}{|c|c|c|}
\hline $\begin{array}{l}\text { Estrutura de } \\
\text { governança }\end{array}$ & Funções & $\begin{array}{c}\text { Benefícios da utilização do regime de } \\
\text { competência puro }\end{array}$ \\
\hline Sumin & $\begin{array}{l}\text { Fomentar a melhoria dos processos } \\
\text { internos das unidades (secretarias ou } \\
\text { qualquer outro centro de resultado } \\
\text { constituído), organizações do Executivo } \\
\text { estadual }\end{array}$ & $\begin{array}{l}\text { Apropriação de custos aos processos } \\
\text { Possibilidade de mensuração da } \\
\text { contribuição financeira de cada unidade } \\
\text { do Executivo para a execução de cada } \\
\text { projeto }\end{array}$ \\
\hline EpR & $\begin{array}{l}\text { Avaliar o impacto dos resultados } \\
\text { entregues à sociedade }\end{array}$ & $\begin{array}{l}\text { Oferecer dados mais objetivos para } \\
\text { avaliação dos resultados entregues à } \\
\text { sociedade } \\
\text { Avaliação dos custos totais por } \\
\text { programa }\end{array}$ \\
\hline
\end{tabular}

Em relação à potencial melhoria da qualidade da informação, a alocação de recursos através da análise de custo-benefício permitiria o melhor impacto social (desde que considerados todos os custos envolvidos, numa visão de custo total). Atualmente, é evidente, pelos documentos consultados, que tais análises não são realizadas antes do projeto ser iniciado e, com ele em andamento, apenas acompanha-se o gasto total realizado na dotação do projeto. Da mesma forma, o reconhecimento dos ativos permanentes relacionados a um determinado projeto apresentaria de forma mais clara a concepção de que investimentos representam aumento do custeio, permitindo análises gerenciais mais conscientes dos impactos futuros dos gastos atuais. Além da alocação, seria possível a análise dos produtos ou resultados entregues à sociedade; sob uma ótica mais ampla, o desempenho de um grupo de projetos ou portfólio e localmente pelas próprias secretarias em relação às suas ações.

Especificamente em relação à apuração dos custos operacionais do governo, cita-se que atualmente os dispêndios realizados com as atividades consideradas meio nas secretarias (aquelas não vinculadas diretamente com a execução de um projeto específico) não são apropriados aos mesmos. Isso impede a identificação do comportamento dos custos nos diversos programas. Sem um sistema de custeio, os escritórios de projetos perdem uma importante atividade e fonte de informação relevante que poderia ser gerada para os gestores públicos e para a sociedade. Impactos financeiros das solicitações de mudanças no escopo, metas ou marcos dos projetos seriam explicitados.

Em relação à accountability, na ótica interna do governo, responsabilizar gestores aumenta o incentivo para eficiente uso dos recursos, o que demanda informação individualizada sobre desempenho à secretaria/órgão/unidade/ projeto e incentivos associados ao desempenho atingido. Como os projetos estruturadores têm caráter transversal em sua execução, abarcam atividades de 
diversas secretarias de governo, a informação sobre o quanto cada secretaria contribui por meio dos seus recursos para o alcance das metas propostas aumenta a accountability e o próprio conceito da contratualização de resultados. Dessa forma, a possibilidade de contrapor resultado obtido com recursos despendidos forneceria um bom padrão para avaliar produtividade e, consequentemente, o pagamento dos prêmios de desempenho. Fora a questão de incentivos ao gestor público (questão que mereceria outra análise), a informação sobre desempenho particularizado é melhorada com o regime de competência.

Contudo, accountability também envolve a capacidade do governo de apresentar o fluxo de suas ações e utilização dos recursos a agentes externos ao governo, como Legislativo, Judiciário e sociedade em geral. A adoção do regime de competência puro promoveria um esclarecimento quanto aos bens e despesas alocados em cada programa. Isso permitiria à sociedade acompanhar os investimentos previstos para cada área e a necessidade de recomposição dos mesmos para substituir bens ultrapassados. Tais mecanismos de participação popular e de controle social poderiam passar por um fortalecimento e esse movimento demonstraria o próprio conceito de democracia. Como a sociedade pode perceber diretamente os resultados alcançados pelos portfólios de projetos, a demonstração das despesas e os custos incorridos no percurso configuram-se como um grande instrumento de transparência. Com uma apuração mais acurada dos fluxos financeiros do estado, informações sobre dívida pública, arrecadação e superávits, necessidade de transferências e execução orçamentária será possível verificar o impacto da gestão realizada em Minas Gerais nas contas do país como um todo.

Em relação à sinalização de melhoria de gestão e diminuição de risco de crédito pelo aumento da transparência, o governo de Minas Gerais interessado em reduzir seu risco de crédito frente à comunidade internacional, com destaque para as instituições de crédito, agências de análise de risco e governos parceiros, pretende produzir documentos financeiros segundo padrões adotados internacionalmente, permitindo maior compreensão da situação econômica em que se encontra o estado. Uma grande oportunidade para a execução da reforma advém da convergência das normas de contabilidade pública brasileiras aos padrões internacionais de contabilidade pública Ipsasb - que estão em processo de tradução neste ano de 2010, e poderá ser um forte indutor para a adoção definitiva do modelo de competência pura (Ifac, 2009). A evolução das práticas contábeis é ponto de avaliação de desempenho da secretaria e cobrada pelo BID e Bird.

Por exemplo, pelas informações coletadas por entrevista na Controladoria do Estado, vê-se que a análise considera os benefícios, mas não con- 
sidera com a mesma ênfase os pontos críticos que serão enfrentados pela administração pública no estado em questão. Um importante papel a ser exercido, para a informação sobre o desempenho dos contratos (no conceito de contratualização), está além do braço do Executivo, mas sob a agenda dos órgãos de controle. Estes deveriam estar aptos a conduzir uma migração da atuação de auditorias de conformidade para auditoria de resultado. Isso envolve o exercício de estimativas e julgamentos significativos, portanto, exercício de certo nível de discricionariedade numa função que costumamos enxergar como vinculada. A informação contábil passa a apresentar uma visão verdadeira e justa (true and fair view) se as transações e outros eventos forem reconhecidos de modo a exprimir a substância econômica e não simplesmente se as regras forem literalmente observadas. A auditoria por resultados prescinde, ainda, da definição de quais sejam os resultados (outcome) e não simplesmente as saídas (outputs) — outra questão que pressupõe o exercício de julgamentos.

O exercício de estimativas e julgamentos na geração e auditoria de informações contábeis é algo salutar à relevância da informação. Portanto, não deve ser visto como um problema ou algo a ser evitado. Pelo contrário, o exercício de julgamentos com responsabilidade em contabilidade deve ser incentivado e ensinado desde a graduação.

Outra questão é o uso de tais informações no processo orçamentário. Não é claro como a discricionariedade permitida pelo regime de competência (por exemplo: associada às escolhas contábeis, como a determinação da vida útil de ativos para cálculo da depreciação) seria utilizada por gestores públicos para cumprir as metas de desempenho. Embora exista vasta literatura sobre manipulação da informação contábil (earnings management) cujo objeto de estudo é a contabilidade financeira empresarial, esse ramo de pesquisa é ignorado no estudo da administração pública. A rigor, também não dispomos de evidências para argumentar que os gestores públicos se comportariam (ou deixariam de se comportar) da mesma forma que os gestores de empresas privadas. Portanto, não propomos nenhuma inferência, mas sugerimos que essa questão passe a ser objeto de pesquisa na gestão pública. Isso permitiria estabelecer uma política contábil ou manter a atual, que a título de exemplo, no estado de Minas, é centralizada e com o controle pleno pela Controladoria Geral (evitando-se abuso ou permissividade de ajustes pelos gestores locais). Também possibilitaria desenvolver os mecanismos para o controle e monitoramento, que interliguem a gestão (acordos para resultados) com os relatórios contábeis (em regime de competência) que melhor indiquem o desempenho daquela. 


\section{Considerações finais}

As reformas administrativas a partir dos anos 1980 emergiram de um ambiente em que a sociedade passou a exigir dos governantes melhoria da qualidade dos serviços públicos e maior transparência nos gastos governamentais, ou seja, os cidadãos queriam que os administradores públicos se preocupassem com os resultados entregues para a comunidade.

Os modelos de gestão mais promissores foram os pautados na administração por resultados, em que o governo estabelece prioridades para as ações governamentais, elabora indicadores de desempenho, objetivos de curto, médio e longo prazos, bem como metas para redução e controle mais eficiente dos gastos (Carvalho, 1997). Assim, o regime de competência passou a ser parte integrante das reformas, pois contribuiria para: melhora na alocação de recursos; fortalecimento da transparência; melhora na apuração dos custos de operação e identificação dos recursos de todo o governo; e melhor visão do impacto do governo na economia (Diamond, 2002).

$\mathrm{O}$ regime de competência é considerado mais completo, uma vez que incorpora as funções desempenhadas pelo regime de caixa e acrescenta diversas informações, permitindo análises financeiras, orçamentárias, patrimoniais e de custos.

Atualmente, o setor público brasileiro no geral adota o regime de competência modificado, contribuindo assim para a valorização da gestão voltada para resultados. Embora o governo federal já esteja implantando seu sistema de custos, ainda é cedo para afirmar que estados e municípios estejam preparados para implantá-lo. Afinal, diversos estados não possuem uma estrutura administrativa capaz de sanear suas contas, além de sofrerem fortemente com a cultura de corrupção que é presente até hoje nas organizações governamentais (Pereira, 2002). A extensão do país, o grau de autonomia política das esferas de poder, estadual e municipal e a diversidade de seus 5 mil municípios são elementos desafiadores em comparação com países europeus que já adotaram tal regime.

Algumas iniciativas isoladas, como o citado caso do estado de Minas Gerais, podem sinalizar outra onda dentro da reforma do Estado brasileiro. Mas outras questões ainda permanecem sem resposta: como a velocidade de mudança de paradigma de auditoria por conformidade para resultados estaria se dando na forma de atuação dos órgãos de controle. Essa migração também nos órgãos de controle seria a pedra de arremate e condição fundamental para coerção de todo o sistema adotado. 
Assim, o debate acerca dos prováveis benefícios que a adoção de um regime de competência puro pode trazer para a gestão governamental está apenas no começo. Muitas análises necessitam ser feitas, pois uma determinação do governo federal para implantação do novo regime causaria um impacto em toda a sociedade. E isso pode estar para acontecer com a adoção das Ipsas, o que induzirá a essa discussão e de maneira muito acelerada. Isso pode gerar um grande processo de aprendizagem, com custos ainda não possíveis de ser mensurados. Este assunto deve vir a ser objeto de estudos quando essa nova regulação contábil efetivamente for aplicada, ensejando mais uma vez a necessidade eminente de se pensar em estudos que auxiliem nesse processo do estado de adaptação à nova estrutura de normas.

Embora este artigo procure desmistificar o regime de competência e como ele afetaria o reconhecimento de receitas e despesas no setor público; e sugira justificativas para a não adoção do regime de competência no setor público brasileiro nos últimos 45 anos e desqualifica tais justificativas no atual cenário tecnológico e jurídico, ainda falta refletir sobre quais serão as consequências da adoção do regime de competência. Como no caso apresentado a respeito das reformas em Minas Gerais na preparação para a adoção do regime de competência. Numa perspectiva prescritiva poder-se-ia até afirmar que os gestores públicos terão à disposição melhores informações contábeis para lhes auxiliar no processo decisório. Apesar dos autores acreditarem nisso, ainda não há como se testar essa hipótese.

Portanto, agora é importante que outras questões sejam analisadas, entre elas se os contadores dos diversos municípios brasileiros (principalmente os de menor porte) estariam preparados para migrar para o regime de competência. Da mesma forma, se os técnicos dos órgãos de controle (principalmente dos tribunais de contas dos estados menos desenvolvidos) estão preparados para fiscalizar contas apuradas com base no regime de competência. Em termos de viabilidade, os esforços para adaptar os sistemas de informação, e quem financiaria tal adaptação também virão a ser alvo de questionamento futuro.

Considerando que já temos um ambiente institucional vigente a respeito da Lei de Responsabilidade Fiscal (LRF), com a adoção de tal regime há que se refletir se os parâmetros econômico-financeiros baseados em dados contábeis estabelecidos pela LRF sofrerão alguma alteração. Já que a LRF é significativa fonte de coerção, como os gestores públicos responderiam à regulação, e se adotariam estratégias já utilizadas por gestores privados, conhecidas como gerenciamento de resultados, ainda devem ser alvo de reflexão cuidadosa. Por fim, a migração do processo orçamentário, de regime de caixa para regime de 
competência (o chamado "accrual budget") traz outros desafios, e não é uma questão fechada, mesmo em outros países que já adotaram o regime de competência na contabilidade financeira (patrimonial).

Esses pontos, ainda sem respostas, dão uma direção da reflexão a ser feita no caso brasileiro. Contudo, apesar de não termos as respostas, esperamos que este artigo contribua com a efetiva adoção do regime de competência na contabilidade financeira (patrimonial) do setor público brasileiro e propicie o desenvolvimento de pesquisas relacionadas ao tema no âmbito dos programas de administração pública.

\section{Referências}

ARNABOLDI, M.; LAPSLEY, I. On the implementation of accrual accounting: a study of conflict and ambiguity. European Accounting Review, v. 18, n. 4, p. 809836, 2009.

BOGT, H. J.; HELDEN, G. J. Accounting change in Dutch government: exploring the gap between expectations and realizations. Management Accounting Research, v. 11, n. 2, p. 263-279, 2000.

BRASIL. Ajuste Sinief 7, de 30 de setembro de 2005. Disponível em: <www. fazenda.gov.br/confaz/confaz/ajustes/2005/AJ_007_05.htm>. Acesso em: 13 mar. 2009.

BORGES, Thiago Bernardo. Regime de competência puro: uma discussão acerca da produção de informações gerenciais a partir da contabilidade pública. 2009. Monografia (Graduação em Ciências Contábeis) — Faculdade de Ciências Econômicas, Universidade Federal de Minas Gerais, Belo Horizonte.

BRESSER-PEREIRA, Luiz Carlos. Da administração pública burocrática à gerencial. Revista do Serviço Público, Brasília, Enap, ano 47, v. 120, n. 1, 1996.

; SPINK, Peter Kevin (Orgs.). Reforma do Estado e administração pública gerencial. Rio de Janeiro: FGV, 1998.

CARDOSO, Fernando Henrique. In: BRESSER-PEREIRA, Luis Carlos; SPINK, Peter Kevin (Orgs.). Reforma do Estado e administração pública gerencial. Rio de Janeiro: FGV, 1998.

CARLIN, Tyrone M. Accrual accounting e financial reporting in the public sector: reframing the debate. MGSM Working Papers in Management. Sydney, Australia: Macquarie Graduate School of Management, Macquarie University, 2003. 
CARVALHO, Wagner. A reforma administrativa na Nova Zelândia nos anos 80-90: controle estratégico, eficiência gerencial e accountability. Revista do Serviço Público, v. 48, n. 3, p. 5-33, set./dez. 1997.

COVALESKI, M. A.; DIRSMITH, M. W.; JABLONSKY, S. F. Traditional and emergent theories of budgeting: an empirical analysis. Journal of Accounting and Public Policy, v. 4, n. 4, p. 277-300, 1985.

DIAMOND, Jack. Performance budgeting: is accrual accounting required? IMF Working Paper, Dec. 2002. Fiscal Affair Department. Disponivel em: <www.blackwellpublishing.com >. Acesso em: out. 2008.

FRANCO, Raquel Andréia. Planejamento público no estado de Minas Gerais: uma trajetória no Estado de Minas Gerais. 2004. Monografia (Graduação em Administração Pública) - Fundação João Pinheiro, Escola de Governo Professor Paulo Neves de Carvalho, Belo Horizonte, 2004.

FREITAS, Vinícius Pimentel de. Documento fiscal eletrônico reduz custos? 2010. Dissertação (Mestrado em Administração) — Escola Brasileira de Administração Pública e de Empresas, Fundação Getulio Vargas (Ebape/FGV).

FURTADO, Rodrigo Guerra. Acordo de resultados em Minas Gerais: uma análise das modificações propostas ao instrumento pelo Projeto de Lei no 1.677 de 2007. 2007. Monografia (Graduação em Administração Pública) — Fundação João Pinheiro, Escola de Governo Professor Paulo Neves de Carvalho, Belo Horizonte, 2007.

GEIGER, D. R. Motivating contingencies act early adopters of federal cost management accounting systems. Government Accountants Journal, v. 44, n. 1, p. 17-30, 1995.

GEIGER, D.; ITTNER, C. The influence of funding source and legislative requirements on government cost accounting practices. Accounting Organizations and Society, v. 21, n. 6, p. 549-567, 1996.

GUIMARÃES, Tadeu B.; ALMEIDA, Bernardo T. Da estratégia aos resultados concretos: a experiência do governo de Minas (2003-2005). CADERNOS BDMG. Belo Horizonte: BDMG, 2006.

HICKS, John Richard. Value and capital. Oxford: Clarendon, 1939.

IFAC (International Federation of Accoutants). Govermnent financial reporting: accounting issues and practices. 2000. Disponível em: < www.ifac.org >. Acesso em: 25 fev. 2009.

. Handbook of international public sector accounting pronouncements. 2009. Disponível em: <www.ifac.org>. Acesso em: 25 fev. 2009. 
IASB (International Accounting Standards Board). International financial reporting standard for small and medium-sized entities (IFRS for SMEs). London: Iasb, 2009. 2010a.

. Framework for the preparation of financial statements. London: Iasb, . International financial reporting standard 41: agriculture (IAS 41). London: Iasb, 2010b.

IPSASB (International Public Sector Accounting Standards Board). International public sector accounting standard 1: presentation of financial statements (Ipsas 1). New York: Ipsasb, 2009a.

. International public sector accounting standard 23: revenue from non-exchange transactions (taxes and transfers) (Ipsas 23). New York: Ipsasb, 2009b. . International public sector accounting standard 27: agriculture (Ipsas 27). New York: Ipsasb, 2009c.

IUDÍCIBUS, Sérgio de; MARTINS, Eliseu; GELBCKE, Enersto Rubens. Manual de contabilidade das sociedades por ações: aplicável às demais sociedades. 7. ed. São Paulo: Altas, 2008.

KOHAMA, H. Contabilidade pública: teoria e prática. São Paulo: Atlas, 2001.

LAPSLEY, I. Responsibility accounting revived? Market reforms and budgetary reforms in health care. Management Accounting Research, v. 5, n. 3-4, p. 337-352, 1994.

.; WRIGHT, E. The diffusion of management accounting innovations in the public sector: a research agenda. Management Accounting Research, v. 15, n. 3, p. 355-374, 2004.

.; MUSSARI, R.; PAULSSON, G. On the adoption of accrual accounting in the public sector: a self-evident and problematic reform. European Accounting Review, v. 18, n. 4, p. 719-723, 2009.

MARTINS, Gilberto; THEOPHILO, Carlos. Metodologia da investigação científica para ciências sociais aplicadas. São Paulo: Atlas, 2007.

MELLETT, H.; MARRIOTT, N.; MACNIVEN, L. Diffusion of an accounting innovation: fixed asset accounting in the NHS in wales. European Accounting Review, v. 18, n. 4, p. 745-764, 2009.

OECD (Organização para o Desenvolvimento e Cooperação Econômica). Model of public budget and accounting reform, v. 2. Paris: OECD, 2002. 
OLIVEIRA, Kamila Pagel de. Gerenciamento dos projetos estruturadores implementados no estado de Minas Gerais: discussão e análise comparativa, a partir da percepção das equipes responsáveis pelo gerenciamento dos projetos voltados para a área de infraestrutura econômica e para a área social. 2006. Monografia (Graduação em Administração Pública) — Fundação João Pinheiro, Escola de Governo Professor Paulo Neves de Carvalho, Belo Horizonte, 2006.

PALLOT, J. New public management reform in New Zealand: the collective strategy phase. International Public Management Journal, n. 1, p. 1-18, 1998.

PECI, Alketa et al. Oscips e termos de parceria com a sociedade civil: um olhar sobre o modelo de gestão por resultados do governo de Minas Gerais. Revista de Administração Pública, v. 42, n. 6, p. 1137-1162, 2008.

PEREIRA, José Matias. Reforma do Estado e transparência: estratégias de controle da corrupção no Brasil. In: CONGRESO INTERNACIONAL DEL CLAD SOBRE LA REFORMA DEL ESTADO Y DE LA ADMINISTRACIÓN PÚBLICA, 7., Lisboa. Anais... Lisboa, Portugal, 2002.

PILCHER, R.; DEAN, G. Consequences and costs of financial reporting compliance for local government. European Accounting Review, v. 18, n. 4, p. 725-744, 2009.

PINA, V.; TORRES, L.; YETANO, A. Accrual accounting in EU local governments: one method, several approaches. European Accounting Review, v. 18, n. 4, p. 765-807, 2009.

REZENDE, Flávio da Cunha. As reformas e as transformações no papel do Estado: o Brasil em perspectiva comparada. In: ABRUCIO, Fernando Luiz; LOUREIRO, Maria Rita. (Orgs.). O Estado em uma era de reformas: os anos FHC. Belo Horizonte, Brasília: MP, Seges, 2002.

ROCKNESS, H.; SHIELDS, M. D. An empirical analysis of the expenditure budget in research and development. Contemporary Accounting Research, p. 568-581, 1986.

SALEH, Zakiah; PENDLEBURY, Maurice W. Accruals accounting in government: developments in Malaysia. Asia Pacific Business Review, v. 12, n. 4, p. 421-435, 2006. Diponível em: <www.routledge.com>.

TIMOTEO, Marcela Oliveira. Gerência de projetos no setor público: adequações e limitações do PMBOK a projetos estruturadores governamentais sociais. 2005. 92f. Monografia (Graduação em Administração Pública) — Fundação João Pinheiro, Escola de Governo Professor Paulo Neves de Carvalho, Belo Horizonte, 2005. 